\title{
Effect of triaxial in situ stresses and heterogeneities on absolute permeability of laminated rocks
}

\author{
Omar A. Almisned ${ }^{1} \cdot$ Abdulrahman A. Al-Quraishi $^{1} \cdot$ Musaed N. Al-Awad $^{2}$
}

Received: 13 January 2015/Accepted: 3 June 2016/Published online: 20 June 2016

(c) The Author(s) 2016. This article is published with open access at Springerlink.com

\begin{abstract}
This work aims at improving our understanding of the effect of triaxial stress on absolute permeability of homogeneous and heterogeneous rocks. Measurements of absolute permeabilities of homogenous and heterogeneous laminated rock samples under hydrostatic and different laboratory-simulated triaxial in situ stress loadings were prepared. Experiments were conducted using homogenous, standard Berea and heterogeneous laminated sandstone cores (with lamination parallel to the flow direction). The effect of in situ stress variation on absolute permeability was investigated. Absolute permeability of homogenous sandstones sample decreased in a uniform manner as the axial load increased below the ultimate shear strength. As axial stress exceeds the radial confining stress, slight increase attributed to microcracks opening was noticed. For laminated sandstones, the scenario is quite different. Permeability shows exactly a similar trend of permeability drop as axial load increases due to inferred matrix compaction. At certain axial load, the permeability starts to increase due to inferred dilatancy of microcracks at the lamina faces and then drops again as axial load increases due to lamina compaction. If the axial load is further increased, pore collapses and grain-to-grain cementing breaks down into pore space followed by microcracks development predominantly parallel to the axial load leading to permeability enhancement. It has been concluded that absolute permeability changes due to lamination opening and closure as a result of loading magnitude
\end{abstract}

Omar A. Almisned

almisned@kacst.edu.sa

1 King Abdulaziz City for Science and Technology, P. O. Box: 6086, Riyadh 11442, Kingdom of Saudi Arabia

2 King Saud University, Riyadh, Kingdom of Saudi Arabia and orientation. It is also concluded that permeability of the formation rock is affected by heterogeneity depending on the direction of lamination as well as the state of the stresses applied and loading type.

Keywords Absolute permeability - Triaxial stress · In situ stresses $\cdot$ Lamination $\cdot$ Heterogeneity $\cdot$ Confining pressure · Microcracks

\section{Introduction}

Many studies to investigate the effect of in situ stresses on absolute permeability at hydrostatic as well as triaxial stress state have been discussed in the literature (Fatt and davis 1952; Mc Latchie et al.1958; Knutson and Bohor 1962; Al-Quraishi and Colin 2003; Belhaj et al. 2004; Dobrynin 1962; Gray et al. 1963; Holt 1990; Jones et al. 2001; Keaney et al. 1998; Lockner et al. 1995; Morita et al. 1984; Putra et al. 2003; Teufel et al. 1993; Wilhelmi and Somerton 1967). The purpose of this study is to investigate the effect of triaxial in situ stress conditions on singlephase (absolute) permeability of laminated rock samples with lamination being parallel to the flow direction heterogeneity.

Absolute permeability is the rock ability to transmit fluid at $100 \%$ saturation with that fluid and is mathematically expressed by Darcy's equation for single-phase flow through porous medium:

$q_{i}=\frac{-k A}{\mu}\left[\frac{\mathrm{d} P_{i}}{\mathrm{~d} x} \pm \rho_{l} g \operatorname{Sin} \theta\right]$

where $q_{i}=$ fluid flow, cc/sec; $A=$ cross-sectional area, $\mathrm{cm}^{2} ; \mu=$ fluid viscosity, $\mathrm{cp} ; \frac{\mathrm{d} P_{i}}{\mathrm{~d} x}=$ pressure gradient along

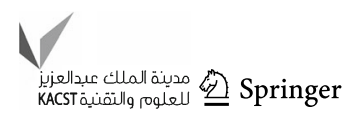


$x$ direction, atm/cm; $\rho=$ fluid density, $\mathrm{gm} / \mathrm{cc} ; g=$ acceleration of gravity, $\mathrm{cm} / \mathrm{sec}^{2} ; k=$ porous medium permeability, Darcy; $\theta=$ angle-measured counter-clockwise from horizontal to the direction of flow.

Permeability is a function of many factors, among these factors and by far the most effective is the confining pressure.

\section{Rock failure criteria}

Non-elastic failure of test rock samples due to triaxial loading may occur if the ultimate strength is exceeded. Therefore, failure criteria must be determined for each type of rocks before testing. The strength of samples has bed tested and calculated using the Mohr-Coulomb rock failure criterion as follows:

$\tau_{\mathrm{f}}=\tau_{\mathrm{o}}+\sigma \cdot \tan (\phi)$

where $\tau_{f}=$ the ultimate shear strength at failure; $\tau_{\mathrm{o}}=$ the apparent cohesive strength; $\sigma=$ the applied normal stress; $\phi=$ the angle of internal friction.

Axial stress at failure and confining pressure values obtained from the triaxial compression tests are used to plot Mohr-Coulomb circles, Fig. 1. Due to the limited number of samples, more conservative failure criterion was determined by conducting at least two unconfined compressive strength $\left(\sigma_{\mathrm{c}}\right)$ tests for each set of cores. The measured unconfined compressive strength was then substituted in the generalized relationship governing average unconfined compressive strength and the apparent cohesive strength $\left(\tau_{\mathrm{o}}\right)$ to calculate sample apparent cohesion as follows (AlAwad (2002)):

$\tau_{\mathrm{o}}=a_{\mathrm{o}}+a_{1} \cdot \sigma_{\mathrm{c}}+a_{2} \cdot \sigma_{\mathrm{c}}^{2}+a_{3} \cdot \sigma_{\mathrm{c}}^{3}+\cdots$

Knowing rock unconfined compressive strength $\left(\sigma_{\mathrm{c}}\right)$ and apparent cohesion $\left(\tau_{\mathrm{o}}\right)$, angle of internal friction $(\phi)$,

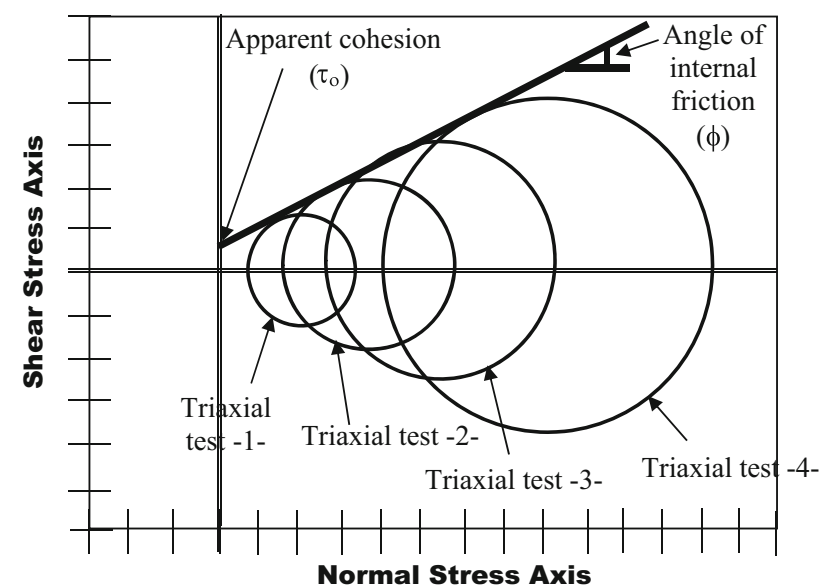

Fig. 1 Typical Mohr-Coulomb failure criterion Al-Awad (2002) required to complete the definition of the failure criterion for the tested rocks, can be calculated using the following well-known one:

$\frac{\sigma_{\mathrm{c}}}{\tau_{\mathrm{o}}}=\frac{2 \cdot \operatorname{Cos}(\phi)}{1-\operatorname{Sin}(\phi)}$

\section{Materials, setup and preparatory measurements}

The heterogeneous samples were specially ordered from an outcrop rock samples provider. The homogenous samples were standard Berea rock samples. All rock samples used in the experiments are 1.5 inches in diameter and 3 inch long. The heterogeneous samples were cut from 2 -ft long samples characterized with structured heterogeneities in the form of zero dip microscale lamination parallel to the flow direction.

Core samples were first fired gradually to $800{ }^{\circ} \mathrm{F}$ to stabilize any clay minerals that may present within. Samples were then weighed dry and placed in a closed desiccator connected to vacuum pump. Evacuation was started, and when proper vacuum was reached, water was let in to saturate the samples under vacuum. To ensure full saturation, wet rock samples were placed on a pressure autosaturator where they were fully saturated overnight at 2500 psi pressure. Wet weight was then measured, and weight difference and water density were used to measure the samples porosities. Samples porosity values were corrected by considering the pore volume reduction due to stresses applied. Figure 2 shows a schematic of the experimental setup. Details of the material preparation and setup were presented in another publication concerned with relative permeabilities (Al-Quraishi et al. (2010)).

\section{Results}

The absolute permeabilities parallel to the long axis of the rock samples and the fore set lamination for heterogeneous samples were measured using gas permeameter and corrected to liquid permeabilities at 400 psi hydrostatic confining pressure. Saturated rock samples under investigation were then loaded in the triaxial core holder with end platens hand-pressed against the sample ends. Low radial load was then applied to hold the sample and portion of the end platens within the sleeve. The core holder assembly was then placed in the loading frame, and hydrostatic axial and radial stresses of 400 psi were applied. Absolute permeability was measured at that hydrostatic condition to double-check the measurement made with the gas permeameter. Good agreement was found between the two measurements (Fig. 3). 
Fig. 2 Schematic of the experimental setup used (AlQuraishi et al. (2010))

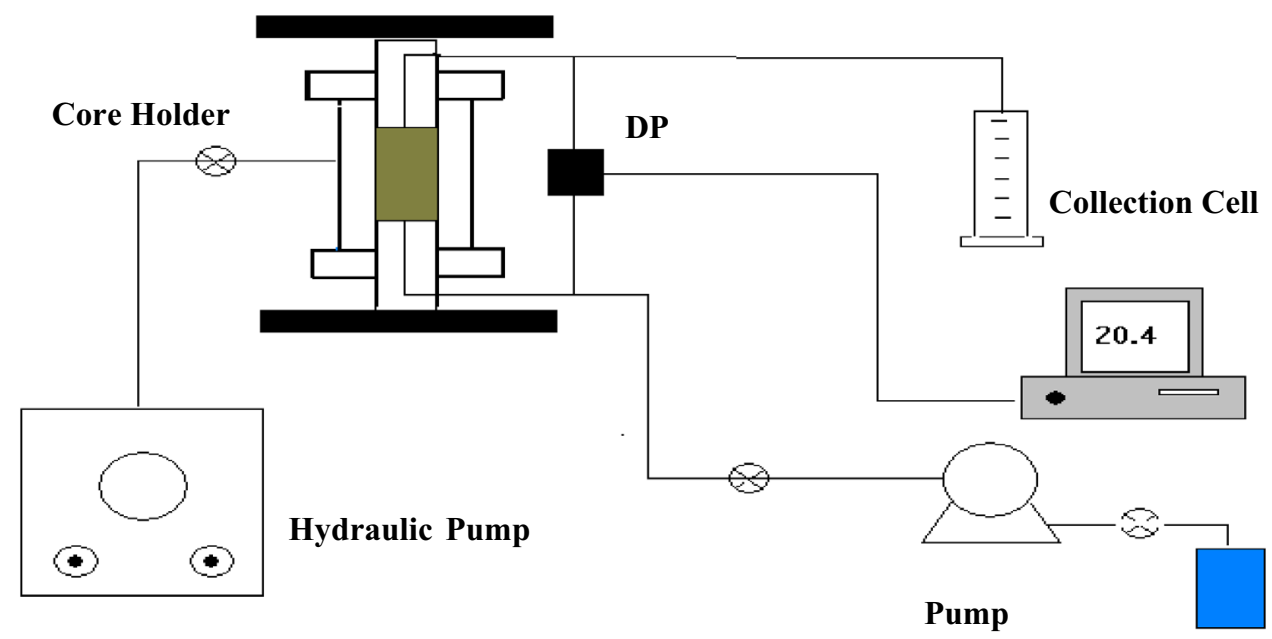

Fig. 3 Relationship between axial stress at failure and confining stress for samples used

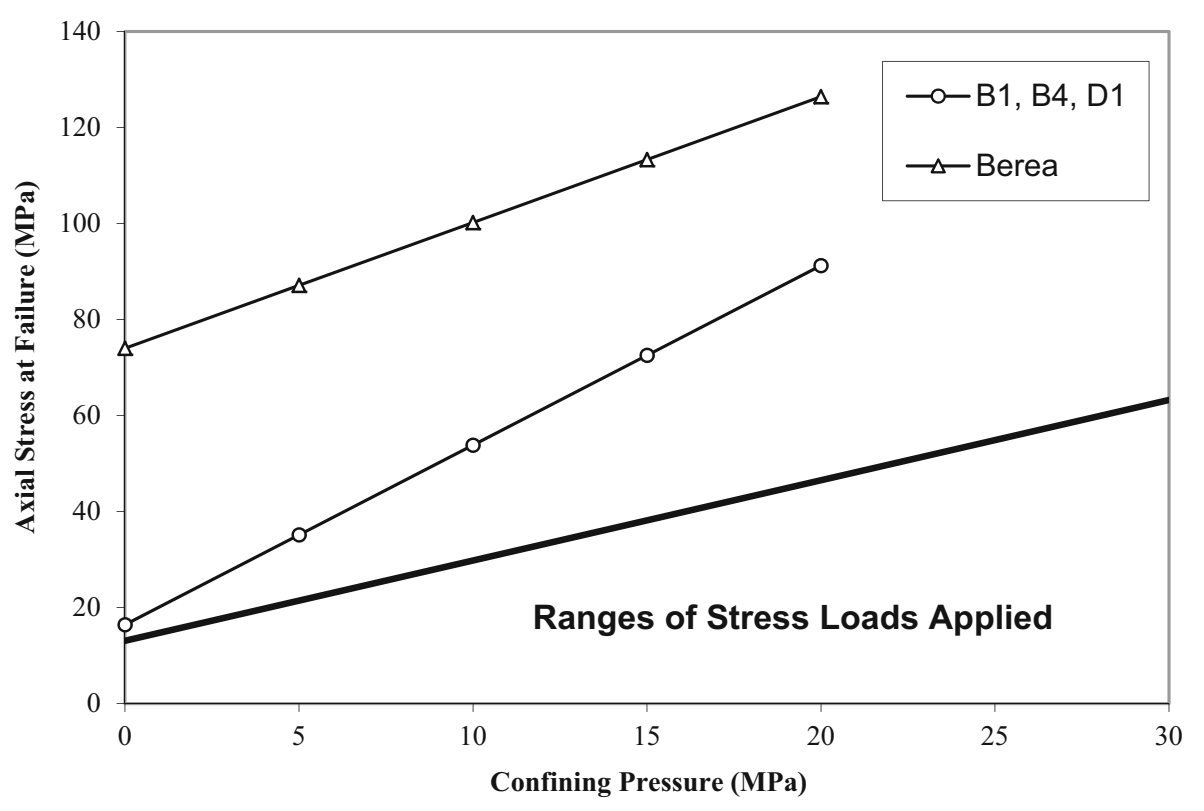

Table 1 lists the mechanical properties of the tested rock samples using typical plot of the relationship between axial load at failure and confining pressure using Mohr-Coulomb failure criteria. Accordingly, triaxial loadings used in this study were selected based on measured failure criteria shown in Fig. 1.

Table 1 Summary of mechanical properties of the tested sandstones

\begin{tabular}{llrll}
\hline $\begin{array}{l}\text { Rock } \\
\text { type }\end{array}$ & $\begin{array}{l}\text { Unconfined } \\
\text { compressive } \\
\text { strength, } \\
\text { psi (MPa) }\end{array}$ & $\begin{array}{l}\text { Apparent } \\
\text { cohesion, } \\
\text { psi (MPa) }\end{array}$ & $\begin{array}{l}\text { Angle of } \\
\text { internal } \\
\text { friction }\left({ }^{\circ}\right)\end{array}$ & $\begin{array}{l}\text { Triaxial } \\
\text { stress } \\
\text { factor }\end{array}$ \\
\hline Berea & $10,730(74)$ & $3321(22.9)$ & 26.6 & 2.62 \\
B and D & $2654(18.3)$ & $995(6.86)$ & 35.2 & 3.72 \\
\hline
\end{tabular}

Table 2 lists the samples physical properties of porosity at atmospheric condition and permeability at hydrostatic confining pressure of 400 psi. While flowing through the sample, radial and axial stresses were ramped up slowly to the predetermined experimental values. At the experimental in situ stress condition, pressure drop across the core sample was recorded at different flow rates and absolute permeability was measured.

To study and compare the effect of triaxial stress conditions on absolute permeability of homogenous and heterogeneous laminated samples, two laminated samples (B and D) and one homogenous sample (Berea) were used. The saturated samples were stressed hydrostatically at 580 psi, and permeability was measured at that stress state. Confining stress was increased to 4000 psi and axial stress was kept at 580 psi and permeability was measured at that 
Table 2 Physical rock properties of the tested samples

\begin{tabular}{lll}
\hline Sample & $\begin{array}{l}\text { Porosity, fraction } \\
\text { @ atmospheric } \\
\text { condition }\end{array}$ & $\begin{array}{l}\text { Absolute permeability, } \\
\text { md @ hydrostatic } \\
\text { pressure of } 400 \text { psi }\end{array}$ \\
\hline Berea & 0.220 & 750 \\
B1 & 0.191 & 172 \\
D1 & 0.206 & 285 \\
\hline
\end{tabular}

Table 3 Summary of experiments conducted

\begin{tabular}{|c|c|c|c|c|}
\hline \multirow[t]{2}{*}{ Sample } & \multirow[t]{2}{*}{ Type } & \multicolumn{2}{|c|}{ Stresses, psi (MPa) } & \multirow{2}{*}{$\begin{array}{l}\text { Loading } \\
\text { type }\end{array}$} \\
\hline & & $\begin{array}{l}\text { Confining } \\
\text { pressure }\left(\sigma_{\mathrm{c}}\right)\end{array}$ & $\begin{array}{l}\text { Axial stress } \\
\left(\sigma_{\mathrm{a}}\right)\end{array}$ & \\
\hline \multirow[t]{2}{*}{ Berea } & \multirow[t]{2}{*}{ Homogenous } & $1000(6.90)$ & $1000(6.90)$ & Hydrostatic \\
\hline & & $1000(6.90)$ & $1914(13.2)$ & Triaxial \\
\hline \multirow[t]{5}{*}{$\mathrm{B} 1$} & \multirow[t]{5}{*}{ Laminated } & $4000(27.60)$ & $1160(8.0)$ & Triaxial \\
\hline & & $4000(27.60)$ & $2320(16.0)$ & Triaxial \\
\hline & & $4000(27.60)$ & $4000(27.6)$ & Hydrostatic \\
\hline & & $1160(8.0)$ & $580(4.0)$ & Triaxial \\
\hline & & $2320(15.93)$ & $580(4.0)$ & Triaxial \\
\hline \multirow[t]{4}{*}{ D1 } & \multirow[t]{4}{*}{ Laminated } & $4000(27.60)$ & \multirow{2}{*}{$\begin{array}{l}4000 \\
\quad(27.60)\end{array}$} & Hydrostatic \\
\hline & & $4000(27.60)$ & & Triaxial \\
\hline & & $4000(27.60)$ & $\begin{array}{l}3000 \\
(20.69)\end{array}$ & Triaxial \\
\hline & & & $2320(16.0)$ & \\
\hline
\end{tabular}

triaxial stress state. Axial stress was ramped up in increments up to 5740 psi, and permeability was measured at each triaxial stress condition.

Table 3 lists the experiments conducted and their corresponding in situ stress conditions. Series of tests were conducted on three samples: two different laminated samples (samples B and D) and one homogeneous sandstone sample (Berea). Permeability of the chosen samples was measured under triaxial loading conditions at constant confining stress of $4000 \mathrm{psi}$. Axial stress was increased and chosen to be below and above the confining radial load but well below the compressive strengths of the rock samples. Samples permeabilities at 580 psi hydrostatic pressure were measured, and each was used as a base value to normalize the permeability values measured. Figures 4,5 and 6 are plots of the normalized permeability versus the axial applied stress for the Berea, B1 and D1 rock samples, respectively. Figure 4 indicates that absolute permeability of homogenous Berea sample decreased in a uniform manner as the axial load increased. This is attributed to the rock experiencing compaction involving elastic closure of existing microcracks and grain boundaries favorably oriented at high angle to axial stress at early stage of loading (near-elastic domain) or due to cementing material detachment announcing pour collapse at late stage of loading (inelastic domain). The trend of decrease is similar to that expected at hydrostatic loading as long as the shear stress is well below yielding (Holt 2001). As axial stress exceeds the radial confining stress of 4000 psi, slight increase was noticed and this can be attributed to microcracks opening. The point of trend reversal corresponds to the onset of dilatancy at which the rate of crack growth dominates over compaction. It should be realized that the degree of permeability drop depends also on the initial permeability value. Highly permeable rocks are expected to be highly affected by axial loading compared to lower permeability ones (Ayan et al. 1994). For laminated sandstones, the scenario is quite different. Figures 5 and 6 are the normalized permeability-axial stress relationships for the two laminated samples B1 and D1, respectively.
Fig. 4 Absolute permeability of Berea homogeneous sample at different axial stresses at 4000 Psi confining stress

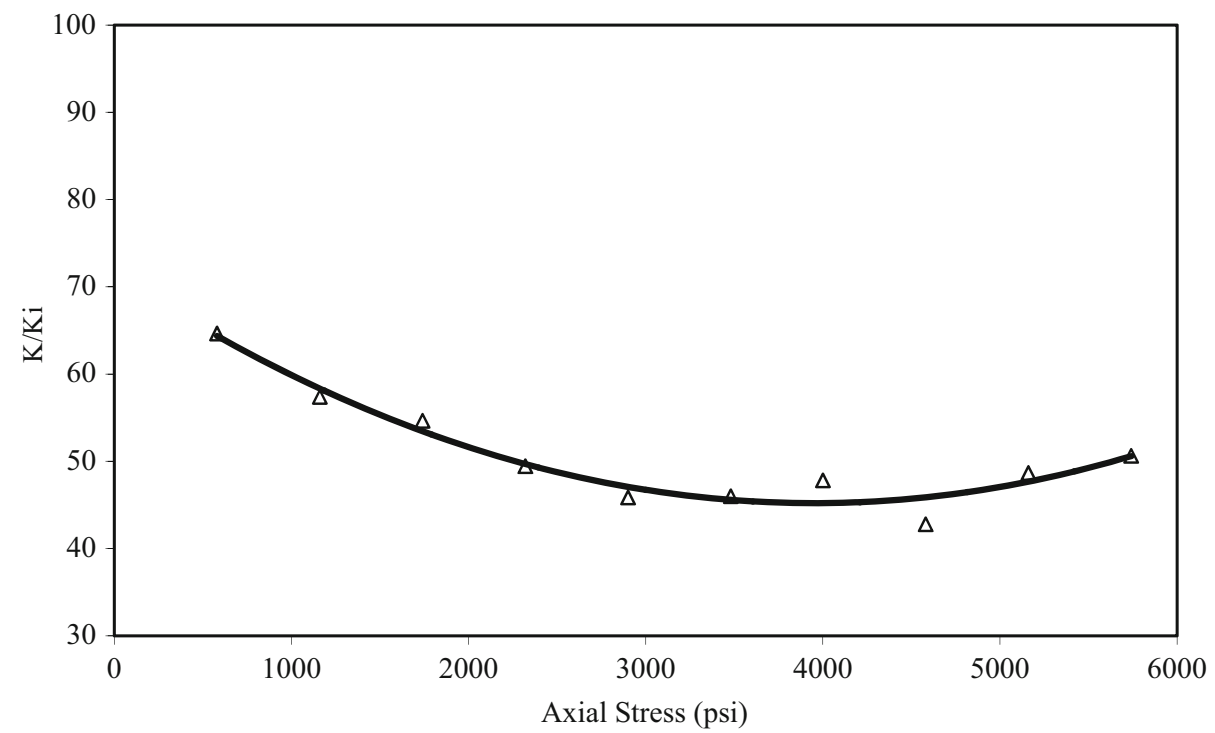


Fig. 5 Absolute permeability of B1-laminated sample at different axial stresses at 4000 Psi confining stress

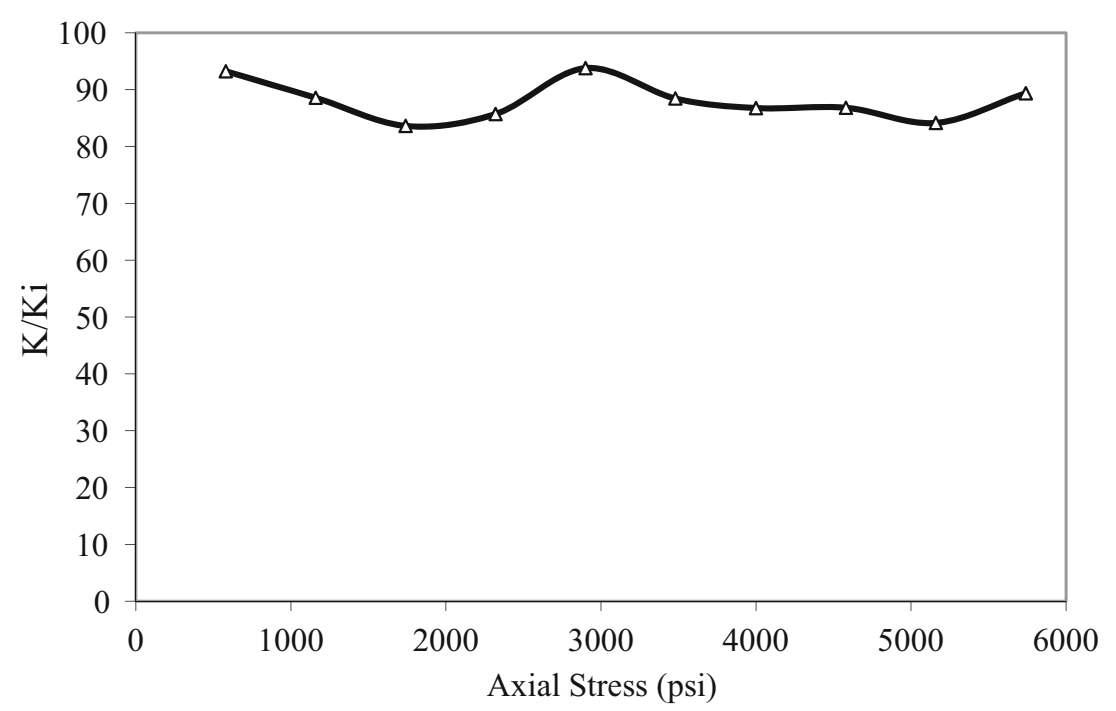

Fig. 6 Absolute permeability of D1-laminated sample at different axial stresses at 4000 Psi confining Stress

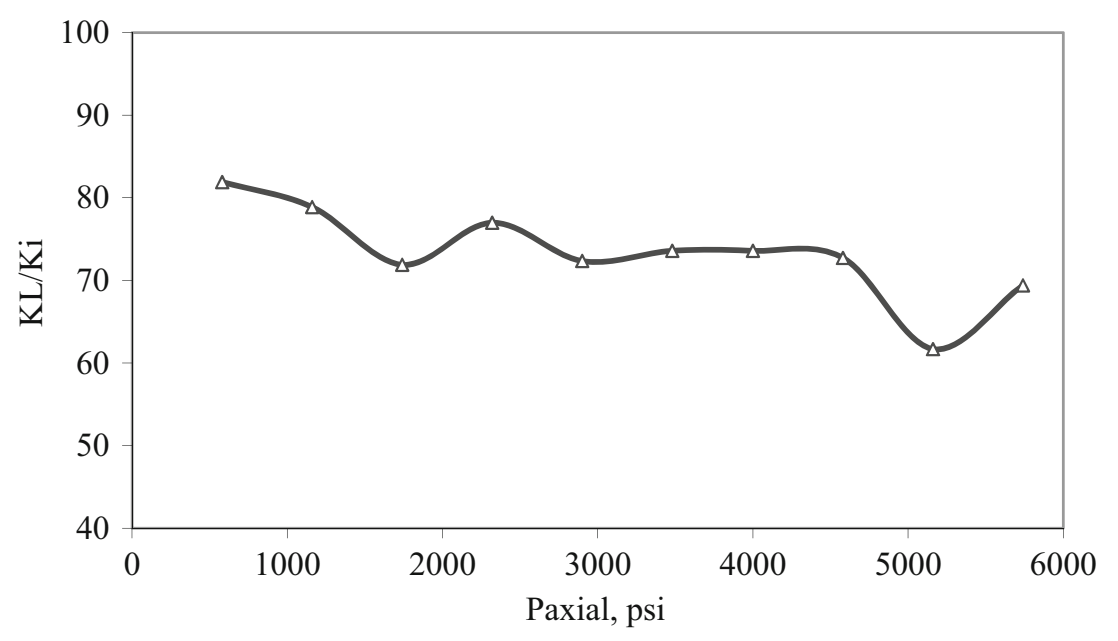

The figures show exactly a similar trend of permeability drop as axial load increases which can be attributed to inferred matrix compaction. At certain axial load, the permeability starts to increase due to inferred dilatancy of microcracks at the lamina faces then drops again as axial load continues to increase probably due to lamina compaction at the inlet and outlet ends of the core sample. If the axial load is further increased pore collapse and grain to grain cementing material break down into pore space will take place followed by microcracks development predominantly parallel to the axial load leading to permeability enhancement.

\section{Conclusions}

Based on the experimental testing performed in this study, the following is concluded:
1. Laboratory-measured permeabilities are significantly different for homogeneous and heterogeneous rocks.

2. The trend of absolute permeability for heterogeneous rocks is highly dependent on the stress loading type during laboratory experiments.

3. Homogeneous rocks permeability is less sensitive to the type of stress loading during laboratory measurements.

4. The effect of lamination parallel to fluid flow direction on reservoir rocks is shown as dynamic crucial changes to the absolute permeability.

Acknowledgments The authors gratefully acknowledge King Abdulaziz City for Science and Technology for supporting this study under KACST's research project number (01-23-NM).

Open Access This article is distributed under the terms of the Creative Commons Attribution 4.0 International License (http:// creativecommons.org/licenses/by/4.0/), which permits unrestricted 
use, distribution, and reproduction in any medium, provided you give appropriate credit to the original author(s) and the source, provide a link to the Creative Commons license, and indicate if changes were made.

\section{References}

Al-Awad MN (2002) Simple correlation to evaluate mohr-coulomb failure criterion using uniaxial compressive strength. J King Saud Univ Eng Sci 14(1):137-145

Al-Quraishi A, Colin Jones (2003) Effect of confining stress on relative permeability. J Eng 13(1):71-77

Al-Quraishi AA, Almisned OA, Al-Awad MNJ (2010) Relative permeabilies of homogeneous and heterogeneous laminated rock samples under hydrostatic and triaxial stresses. J King Saud Univ Eng Sci 22(2):101-110

Ayan C, Colley N, Cowan G, Ezekwe E, Wannell M, Good P, Halford F, Joseph J, Mongini A, Obondoko G, Pop J (1994) Measuring permeability anisotropy: the latest approach. Oilfield Rev 24-35

Belhaj HA, Ryan RJ, Nouri AM, Butt SD, Islam RM (2004) A new coupled fluid flow/stress model for porous media behavior: numerical modeling and experimental investigation. Paper SPE 90265, presented at the 2004 SPE international petroleum conference in Mexico held in Puebla, Mexico Nov 8-9

Dobrynin VM (1962) Effect of overburden pressure on some properties of sandstones. SPE J 2:360-366

Fatt I, Davis DH (1952) Reduction in permeability with overburden pressure. JPT (Dec 1952) 4:16

Gray HD, Fatt I, Bergamini G (1963) The effect of stress on permeability of sandstone cores. SPE J 3:95-100

Holt RM (1990) Permeability reduction induced by non-hydrostatic stress field. SPE Form Eval, pp 444-448, Dec 1990

Holt RM (2001) Petrophysics under stress. Presented at the 6th Nordic symposium on petrophysics, held in Trondheim, Norway, 15-16 May 2001
Jones C, Somrville JM, Smart BGD, Kirstetter O, Hamilton SA, Edlmann KP (2001) Permeability predictions using stress sensitive petrophysical properties. Pet Geosci 7(2):211-219

Keaney GMJ, Meredith PG, Murrell SAF (1998) Laboratory study of permeability evolution in a 'tight' sandstone under non-hydrostatic stress conditions, SPE/ISRM 47265 presented at the Eurock '98 held in Trondheim, Norway, 8-10 July 1998

Knutson CF, Bohor BF (1962) Reservoir rock behaviour under moderate confining pressure. Fifth symposium on rock mechanics, pp 627-659

Lockner D, Naka H, Tanaka H, Ito H, Ikeda R (1995) Permeability and strength of core samples from the nojima fault of the 1995 Kobe Earthquake. In: Proceeding of the International workshop on the Nojima Fault core and borehole data analysis preliminary report, pp 147-152

Mc Latchie AS, Hemstock RA, Young JW (1958) The effective compressibility of reservoir rock and its effects on permeability. Trans AIME 213:386-388

Morita N, Gray KE, Srouji F AA, Jogi PN (1984) Rock property change during reservoir compaction. Paper SPE13099 presented at the annual technical conference and exhibition held in Huston, TX, 1984

Putra E, Muralidbaran V, Schechter D (2003) Overburden pressure affects fracture aperture and fracture permeability in a fractured reservoir. Saudi Aramco J Technol Summer 2003

Teufel LW, Rhett DW, Farrel HE, Lorenz JC (1993) Control of fractured reservoir permeability by spatial and temporal variations in stress magnitude and orientation. Paper SPE 26437 presented at the annual technical conference and exhibition held in Huston, TX, 1993

Wilhelmi B, Somerton WH (1967) Simultaneous measurement of pore and elastic properties of rocks under triaxial stress conditions. SPEJ 7:283-294 